\title{
BIOMETRIA DOS FRUTOS E USO DE ÁCIDO GIBERÉLICO NA GERMINAÇÃO DE SEMENTES DE ABIEIRO (Pouteria caimito)
}

\author{
Bruno Henrique Leite Gonçalves ${ }^{1 *}$, Rafael Augusto Ferraz ${ }^{2}$, Jackson Mirellys Azevêdo \\ Souza $^{3}$, Marco Antonio Tecchio ${ }^{4}$
}

\footnotetext{
${ }^{1}$ Doutorando em Agronomia/Horticultura - Universidade Estadual Paulista (UNESP), Faculdade de Ciências Agronômicas, Campus de Botucatu, SP. *Email do autor correspondente: bruno_lleite@ hotmail.com

${ }^{2}$ Doutor em Agronomia/Horticultura - Universidade Estadual Paulista (UNESP), Faculdade de Ciências Agronômicas, Campus de Botucatu, SP.

3 Pós-doutorando em Agronomia/Horticultura - Universidade Estadual Paulista (UNESP), Faculdade de Ciências Agronômicas, Campus de Botucatu, SP.

${ }^{4}$ Professor Doutor do departamento de Horticultura - Universidade Estadual Paulista (UNESP), Faculdade de Ciências Agronômicas, Campus de Botucatu, SP.
}

RESUMO: No Brasil, existem diversas espécies de frutíferas nativas que ainda são pouco cultivadas, mas com grande potencial de exploração comercial, especialmente na região amazônica. Desta forma essa pesquisa teve como objetivo avaliar a biometria dos frutos e o uso de ácido giberélico na germinação das sementes do abieiro. $\mathrm{O}$ primeiro experimento consistiu na avaliação da biometria dos frutos em amostra de 50 frutos, avaliaram-se: massa fresca do fruto, da casca, da polpa e da semente, número de sementes, comprimento longitudinal e diâmetro dos frutos. Amostras de frutos foram trituradas e no mosto avaliaram-se o $\mathrm{pH}$, teor de sólidos solúveis e acidez. O segundo experimento consistiu na avaliação da germinação de sementes de abieiro imersas em soluções de ácido giberélico $\left(\mathrm{AG}_{3}\right)$ nas doses de: $0,50,100,150$ e $200 \mathrm{mg} \mathrm{L}^{-1}$. O delineamento experimental foi em parcelas subdivididas, com quatro repetições e 25 sementes por repetição. As parcelas corresponderam às doses do regulador vegetal, enquanto que as subparcelas corresponderam aos dias de avaliação após a semeadura $(7,9,11,13,15,17,19,21,23,25,27,29,31,33$ e 35 dias). Foram avaliados a porcentagem de germinação, o tempo médio de germinação (TMG) e o índice de velocidade de germinação (IVG). Observou-se para o peso do fruto e o número da semente variabilidade média, enquanto que as demais características físicas e químicas apresentaram baixa variabilidade. $\mathrm{O}$ uso do ácido giberélico, não incrementou a porcentagem da germinação.

Palavras-chave: Produção. Fruticultura. Abiú. Reguladores vegetais.

\section{BIOMETRY OF FRUITS AND USE OF GIBBERELLIC ACID ON SEED GERMINATION OF ABIU (Pouteria Caimito)}

\begin{abstract}
In Brazil, there are several species of native fruit trees that are still few, but with great potential for commercial exploitation, especially in the Amazon region. In this waythis rese-arch aimed to evaluate the biometry of fruits and the use of gibberellic acidon germination of seeds of pouteria caimito. The first experiment consisted in evaluating the biometrics of the fruits in 50 sample fruits were evaluated: fresh fruit, Peel, seed and pulp,
\end{abstract}

Cultura Agronômica, Ilha Solteira, v.26, n.4, p.530-539, 2017 
seed number, len-gth and diameter of the fruit. Fruit samples were crushed and evaluated inmash $\mathrm{pH}$, soluble solids content and acidity. The second experiment was to evaluate the germination of seeds of pouteria caimito immersed in soluti-ons of gibberellic acid (AG3) at doses of $0,50,100,150$ and $200 \mathrm{mg} \mathrm{L}-1$. The experimental was on plots subdivided, with four repetitions and 25 seeds por repetition. The plots corresponded to doses of plant regulator, while the subplots corresponded to asessment days after sowing $(7,9,11,13,15$, $17,19,21,23,25,27,29,31,33$ and 35 days). The germination percentage were evaluated, the average germination time (TMG) and the germination speed in-dex (IVG). The weight of the fruit and seednumber, average variability, for the other physical and chemical characteristics are low variability. The use of gibberellic acid, not increased the percentage of germination.

Key words: Production. Fruit. Abiu. Vegetable regulators.

\section{INTRODUÇÃO}

Em regiões tropicais e subtropicais do mundo há a possibilidade de cultivo de grande diversidade de espécies frutíferas, a maior parte destas apresentam frutos com grande potencial para alimentação e consequentemente para o cultivo comercial, devido, principalmente, pela excelente qualidade e benefícios à saúde. $\mathrm{O}$ consumo de frutas e hortaliças sempre foi valorizado em função dos benefícios que esses alimentos podem trazer à saúde, como fonte de vitaminas, minerais e fibras. Além da importância nutricional, alguns destes compostos, possuem ação antioxidante e podem prevenir ou retardar o aparecimento de doenças, como o câncer (SEGANTINI et al., 2012).

O interesse do consumidor nacional e internacional, pela alimentação saudável e natural, motivou a procura por frutas nativas e exóticas, que vem se tornando um mercado interessante para produtores rurais que procuram alternativas de fonte de renda. (PINTO, 2013). Perspectivas promissoras para exportação de frutos tropicais e subtropicais, se devem aos níveis considerais de compostos bioativos destes frutos (RUFINO et al., 2010)

O abieiro (Pouteria caimito), espécie amazônica e pertencente à família das sapotáceas, é uma árvore de 5 a 6 m de altura; com folhas pecioladas e glabras; frutos de forma ovóide ou esférica com casca amarela e lisa, às vezes amarela com estrias verdes, com massa entre 300 e $1.000 \mathrm{~g}$, polpa translúcida, branca ou amarela, mucilaginosa, doce ou insípida, contendo de 1 a 5 sementes grandes e lisas de cor preta e com grande aceitação popular, utilizado em sua maioria na forma in natura (DONADIO et al., 1992).

Em função dessas características, justifica-se a realização de estudos relacionados à estimativa de parâmetros biométricos, como análise preliminar em vista da facilidade e rapidez da aplicação (ARAÚJO et al., 2012), para a conservação e exploração dos recursos de valor econômico, permitindo um incremento contínuo da busca racional e uso eficaz dos frutos e sementes (GUSMÃO et al., 2006); conforme foi verificado por Ramos e Ferraz 
(2008) com a espécie Enterolobium schomburgkii e Bezerra et al. (2012) em sementes de canafístula (Cassia grandis L. f.).

A produção de mudas constitui-se em uma das etapas mais importantes do sistema produtivo, influenciando diretamente no desempenho da planta. Assim o sucesso da instalação de um pomar de frutíferas é garantido pelo uso de mudas de alta qualidade, homogêneas, de rápida formação e com precocidade na produção (NATALE et al., 2004).

Técnicas que induzem melhoria na qualidade fisiológica das sementes são importantes para aumentar o potencial de desempenho das mesmas e, por conseguinte, a uniformidade das plantas em condições de campo. A embebição das mesmas em água ou utilização de solução com substâncias promotoras da germinação constituem-se em técnicas conhecidas há vários anos e que podem ser utilizadas com sucesso em sementes (ARAGÃO et al., 2006).

O uso de reguladores vegetais pode favorecer o desempenho das plântulas, acelerando a velocidade de emergência de sementes de várias espécies. Segundo Khan (1978), o uso de compostos químicos biologicamente ativos, como reguladores de crescimento, pode cessar ou diminuir o impacto de fatores adversos na qualidade e desempenho das sementes. $\mathrm{O}$ uso de giberelinas na fase de germinação pode melhorar a germinação de sementes de várias espécies, principalmente sob condições adversas.

Entretanto, são escassos estudos de germinação com sementes de abieiro, principalmente em relação às doses ideais de reguladores vegetais necessárias para promover uma melhor germinação de suas sementes. Neste contexto, o presente trabalho teve como objetivo avaliar as características físicas e químicas de frutos de abiu e o uso de ácido giberélico na germinação das sementes de abieiro.

\section{MATERIAL E MÉTODOS}

Realizaram-se dois experimentos no período de setembro a novembro de 2012, em casa de vegetação e no laboratório de Fruticultura do Departamento de Horticultura, da Faculdade de Ciências Agronômicas de Botucatu-SP.

No primeiro experimento foram amostrados frutos maduros de abieiro, coletados aleatoriamente de 5 plantas com 20 anos de idade, no pomar da Faculdade de Ciências Agronômicas - UNESP/Botucatu. Nas cinco plantas, foram colhidos 10 frutos de todos os quadrantes, divididos em cinco repetições de 10 frutos, totalizando 50 frutos. Avaliaram-se as variáveis físicas dos frutos: massa fresca $(\mathrm{g})$, utilizando-se balança analítica com precisão de $0,1 \mathrm{~g}$; diâmetros longitudinal e equatorial dos frutos $(\mathrm{mm})$, obtidos com auxílio de paquímetro digital; relação entre diâmetro longitudinal e equatorial (DL/DE); massa da polpa e de casca $(\mathrm{g})$ por fruto; e número e peso das sementes. Quanto às variáveis químicas, avaliaram-se a acidez titulável, expressa em gramas de ácido cítrico por $100 \mathrm{ml}$ de suco; teor de sólidos solúveis, expressos em ${ }^{\circ}$ Brix e obtido com o auxílio de refratômetro digital; relação SS/Acidez (Ratio), obtido pela relação entre sólidos solúveis e acidez titulável; e o

Cultura Agronômica, Ilha Solteira, v.26, n.4, p.530-539, 2017 
pH. Com os resultados obtidos, calculou-se para as variáveis avaliadas as médias, coeficiente de variação, desvio padrão e valores mínimos e máximos.

No segundo experimento, coletaram-se frutos maduros de cinco plantas adultas. Após a colheita, as sementes foram extraídas dos frutos e lavadas em água corrente para a remoção da mucilagem. Posteriormente, as sementes foram mantidas em bandejas de argila em temperatura ambiente por três dias para a secagem.

Os tratamentos consistiram na imersão das sementes em soluções contendo ácido giberélico $\left(\mathrm{AG}_{3}\right)$ nas doses de: 0, 50, 100, 150 e $200 \mathrm{mg} \mathrm{L}^{-1}$. A fonte de $\mathrm{AG}_{3}$ utilizada foi o produto comercial PROGIBB®, que contém $10 \%$ de $\mathrm{AG}_{3}$. A aplicação dos tratamentos foi realizada mediante a imersão das sementes em becker contendo $500 \mathrm{ml}$ da solução de $\mathrm{AG}_{3}$, por um período de $24 \mathrm{~h}$, durante o qual foi utilizado sistema de aeração. Após a embebição, as sementes foram dispostas em folhas de papel germitest e acondicionadas em câmara do tipo BOD, à temperatura de $25{ }^{\circ} \mathrm{C}$. O delineamento experimental foi em parcelas subdivididas, com quatro repetições e 25 sementes por repetição. As parcelas corresponderam às doses do $\mathrm{AG}_{3}$, enquanto que as subparcelas corresponderam aos dias de avaliação após a semeadura $(7,9,11,13,15,17,19,21,23,25,27,29,31,33$ e 35 dias).

Foram avaliados a porcentagem (\%) de germinação, o tempo médio de germinação (TMG) em dias e o índice de velocidade de germinação (IVG). Os dados obtidos foram submetidos à análise de variância e análise de regressão polinomial, ao nível de 5\% de probabilidade por meio do software Sigma Plot.

\section{RESULTADOS E DISCUSSÃO}

\section{Experimento 1}

Os valores médios da massa fresca, diâmetro e comprimento foram, respectivamente, 52,16 g, 43,39 e 49,02 mm, com valores de massa fresca variando entre 35,09 a 80,09 g, comprimento de 41,30 a 54,70 mm e diâmetro de 38,40 a 51,70 mm (Tabela 1). Carvalho e Muller (2005) obtiveram resultados superiores, obtendo-se o comprimento de $100 \mathrm{~mm}$ e 70 $\mathrm{mm}$ de diâmetro, e o peso de $150 \mathrm{~g}$ do fruto. Essas diferenças podem estar relacionadas tanto nas variações ambientais locais, como o manejo nutricional e o recurso hídrico, o que podem favorecer as características físicas da espécie. Diante desses resultados verificou-se que os frutos do abieiro apresentaram média variabilidade de massa fresca e baixa variabilidade de diâmetro e comprimento na região de Botucatu, para as variáveis avaliadas, proporcionando colheita padronizada para comercialização.

Os valores médios de massa fresca da casca, da polpa e da semente foram de, respectivamente, 23,56, 20,32 e 24,89 g, com os limites mínimos e máximos de, respectivamente, 20,10 a $29 \mathrm{~g}, 18,40$ a $23,30 \mathrm{~g}$ e 3,91 a 4,10 g. Os valores obtidos foram superiores aos encontrados por Carvalho et al. (1998) relataram que o peso da semente em abiu é de $3,72 \mathrm{~g}$. 
A faixa de $\mathrm{pH}$ variou de 5,43 a 6,18, para a acidez titulável, os valores variaram de 0,73 a 0,94 \% de ácido cítrico. Os valores de sólidos solúveis variaram de 10,90 a 13,60 ${ }^{\circ}$ Brix. Estes resultados foram superiores aos obtidos por Canuto et al. (2010), que analisaram frutos de abiu da região amazônica obtiveram os respectivos valores $\mathrm{pH}$, sólidos solúveis e acidez, de, respectivamente, 5,0; 3,8 ${ }^{\circ}$ Brix e 5,9 g expressa em \% de ácido cítrico. As características químicas do abieiro podem variar conforme a genética das plantas assim como conforme as diferentes regiões do Brasil, em função de fatores como umidade, temperatura, período de luz e distribuição de luz. Estes resultados estão próximos aos dados obtidos por Pinto (2013), onde trabalhou-se com armazenamento de frutos com MCP (metilciclopropeno) e obteve valores de 11,28 a 12,56 ${ }^{\circ}$ Brix. Ainda os resultados obtidos estão superiores aos dados encontrado por Virgolin (2015) que avaliou frutos de abieiros em Jaboticabal-SP, obtendo-se sólidos solúveis de 3,8 ( ${ }^{\circ}$ Brix). Canuto et al. (2010), ressaltaram que o teor de sólidos solúveis apresenta correlação com os teores de acidez e açúcares. Tais autores destacam ainda, que este fato é de interesse para o mercado consumidor, uma vez que o mesmo tem predileção por frutas doces.

Tabela 1. Valores médios das variáveis físicas: peso, diâmetro, comprimento, peso casca, peso polpa, número de semente e peso da semente; e das variáveis físico-químicas: sólidos solúveis, pH e acidez. Botucatu, 2012.

\begin{tabular}{lccccc}
\hline \multicolumn{1}{c}{ Variáveis } & Média & $\begin{array}{c}\text { Desvio } \\
\text { padrão }\end{array}$ & $\begin{array}{c}\text { CV } \\
(\boldsymbol{\%})\end{array}$ & Mínimo & Máximo \\
\hline Peso $(\mathrm{g})$ & 52,16 & 12,00 & 23,01 & 35,59 & 80,09 \\
Diâmetro $(\mathrm{mm})$ & 43,39 & 3,73 & 8,60 & 38,40 & 51,70 \\
Comprimento $(\mathrm{mm})$ & 49,02 & 3,41 & 6,95 & 41,30 & 54,70 \\
Peso de casca $(\mathrm{g})$ & 23,56 & 3,23 & 13,72 & 20,10 & 29,00 \\
Peso de polpa $(\mathrm{g})$ & 20,32 & 1,75 & 8,63 & 18,40 & 23,30 \\
$\mathrm{~N}^{\circ}$ de sementes & 24,89 & 12,24 & 49,18 & 3,00 & 10,00 \\
Peso semente $(\mathrm{g})$ & 4,10 & 4,23 & 3,96 & 3,91 & 4,10 \\
Sólidos solúveis $\left({ }^{\circ}\right.$ Brix) & 12,22 & 1,05 & 8,59 & 10,90 & 13,60 \\
pH & 5,88 & 0,25 & 4,24 & 5,43 & 6,18 \\
Acidez titulável $(\%$ de ácido cítrico) & 0,85 & 0,08 & 9,52 & 0,73 & 0,94 \\
\hline
\end{tabular}

\section{Experimento 2}

Não houve interação entre os fatores doses de $\mathrm{AG}_{3}$ e dias de avaliação após a semeadura, assim como não houve também efeito isolado das doses deste produto, de modo que as médias não se ajustaram a nenhuma equação na análise de regressão. Todavia, verificou-se efeito isolado e significativo do fator dias de avaliação após a semeadura para todas as características avaliadas (Tabela 2).

Leonel et al. (1993), em experimento com citros, verificaram que os tratamentos com o ácido giberélico não apresentaram efeito significativo sobre o tempo médio e sobre a velocidade de germinação, no entanto foram eficientes quanto à porcentagem de germinação das sementes. De acordo com Taiz e Zeiger (2010), o equilíbrio entre hormônios, 
promotores e inibidores exerce papel fundamental na promoção da germinação e no crescimento inicial de plântulas, podendo ser a utilização de bioestimulantes uma alternativa promissora para se obter este resultado.

Tabela 2. Valores do teste F, coeficientes de variação (CV) e médias de porcentagem (\%) de germinação, tempo médio de germinação (TMG) em dias e o índice de velocidade de germinação (IVG). Botucatu, 2012.

\begin{tabular}{llccc}
\hline \multicolumn{1}{c}{ FV } & GL & $\begin{array}{c}\text { Porcentagem de } \\
\text { germinação }\end{array}$ & $\begin{array}{c}\text { Tempo médio de } \\
\text { germinação }\end{array}$ & $\begin{array}{c}\text { Índice de } \\
\text { velocidade de } \\
\text { germinação }\end{array}$ \\
\hline Bloco & 3 & $1,00^{\mathrm{ns}}$ & $68338.24^{\mathrm{ns}}$ & $93,66^{\mathrm{ns}}$ \\
Doses & 4 & $0,01^{\mathrm{ns}}$ & $1,61^{\mathrm{ns}}$ & $1,03^{\mathrm{ns}}$ \\
Dias & 28 & $0,001^{*}$ & $71,56^{*}$ & $10,22^{*}$ \\
Doses x Dias & 112 & $0,01^{\mathrm{ns}}$ & $0,01^{\mathrm{ns}}$ & $0,83^{\mathrm{ns}}$ \\
\hline $\mathrm{CV}_{1}(\%)$ & & 2,42 & 2,37 & 86,09 \\
$\mathrm{CV}_{2}(\%)$ & 12,34 & 21,35 & 52,68 \\
Média & & 83,99 & 2,10 & 0,63 \\
\hline
\end{tabular}

ns = não significativo; $*$ = significativo a $5 \%$; ** = significativo a $1 \%$ pelo teste $\mathrm{F}$.
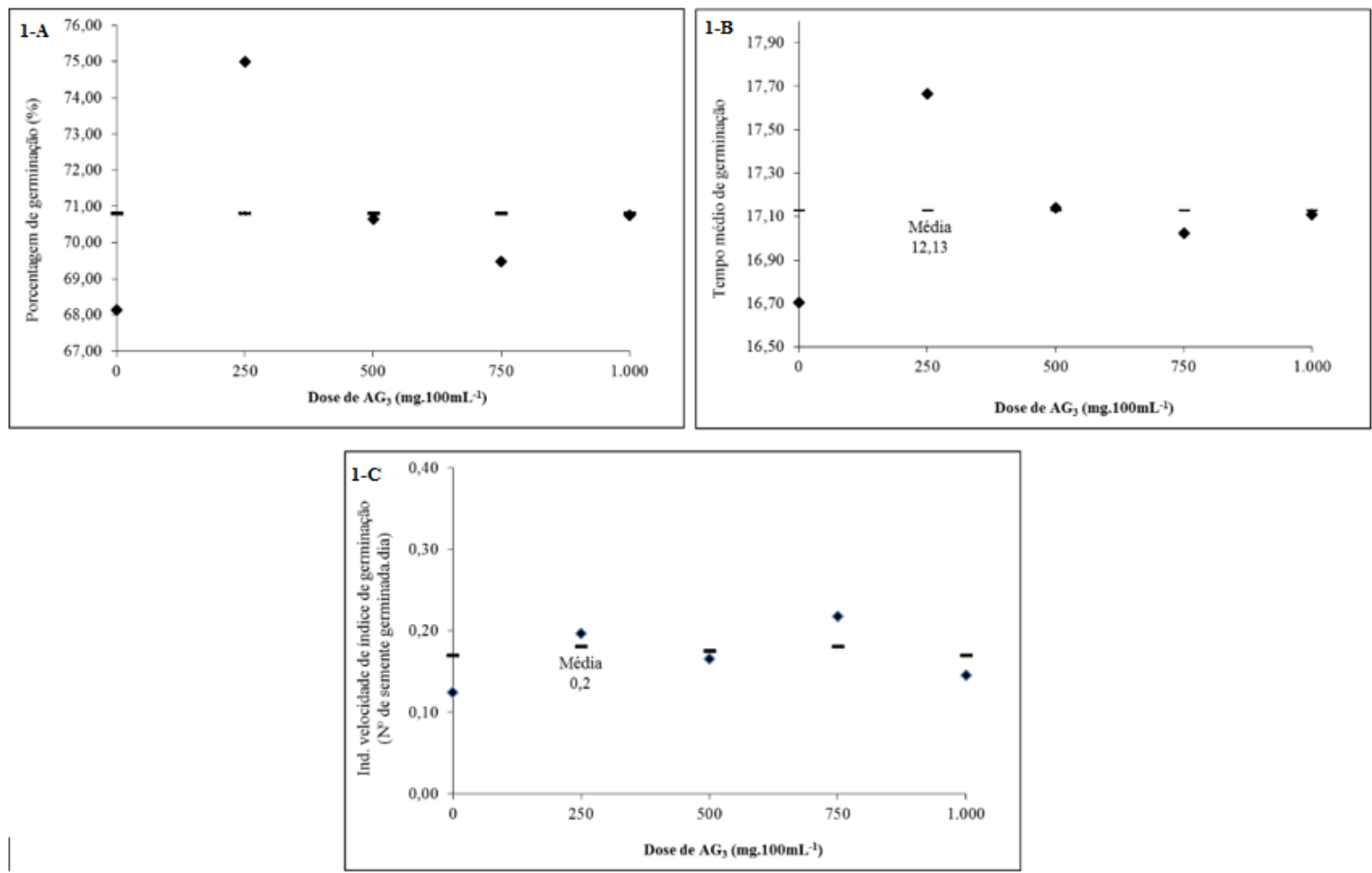

Figura 1. Flutuação e média dos dados de porcentagem de germinação (A), tempo médio de germinação e índice de velocidade de germinação (C) em função das doses de ácido giberélico. Botucatu, 2012.

A flutuação dos dados em função das doses de germinação, tempo médio de germinação e índice de velocidade de germinação podem ser observadas na Figura 1. 
Contudo, vale salientar que a cultivar, assim como as condições de cultivo também podem afetar a qualidade e vigor das sementes.

Quando avaliado o desempenho germinativo das sementes em função dos dias após a semeadura, verificou-se que as primeiras sementes germinaram após sete dias (Figura 2). Os modelos de regressão quadrático foram significativos para expressar o aumento na porcentagem de germinação e do tempo médio de germinação das sementes em função dos dias após a semeadura, com ponto de máximo de, 28,2 e 35 dias. A porcentagem de germinação encontrada no presente trabalho foi superior a $90 \%$, o que corrobora com Nascimento et al. (2006), que reportam uma porcentagem de germinação de $91 \%$ de abeiro cultivado na Amazônia. Estes autores observaram que a maior parte das sementes germinam apenas após 25 dias da semeadura, enquanto no presente trabalho a maior parte das sementes germinaram após o vigésimo dia, embora o ponto máximo tenha sido alcançado somente aos 28,2 dias (Figura 2).
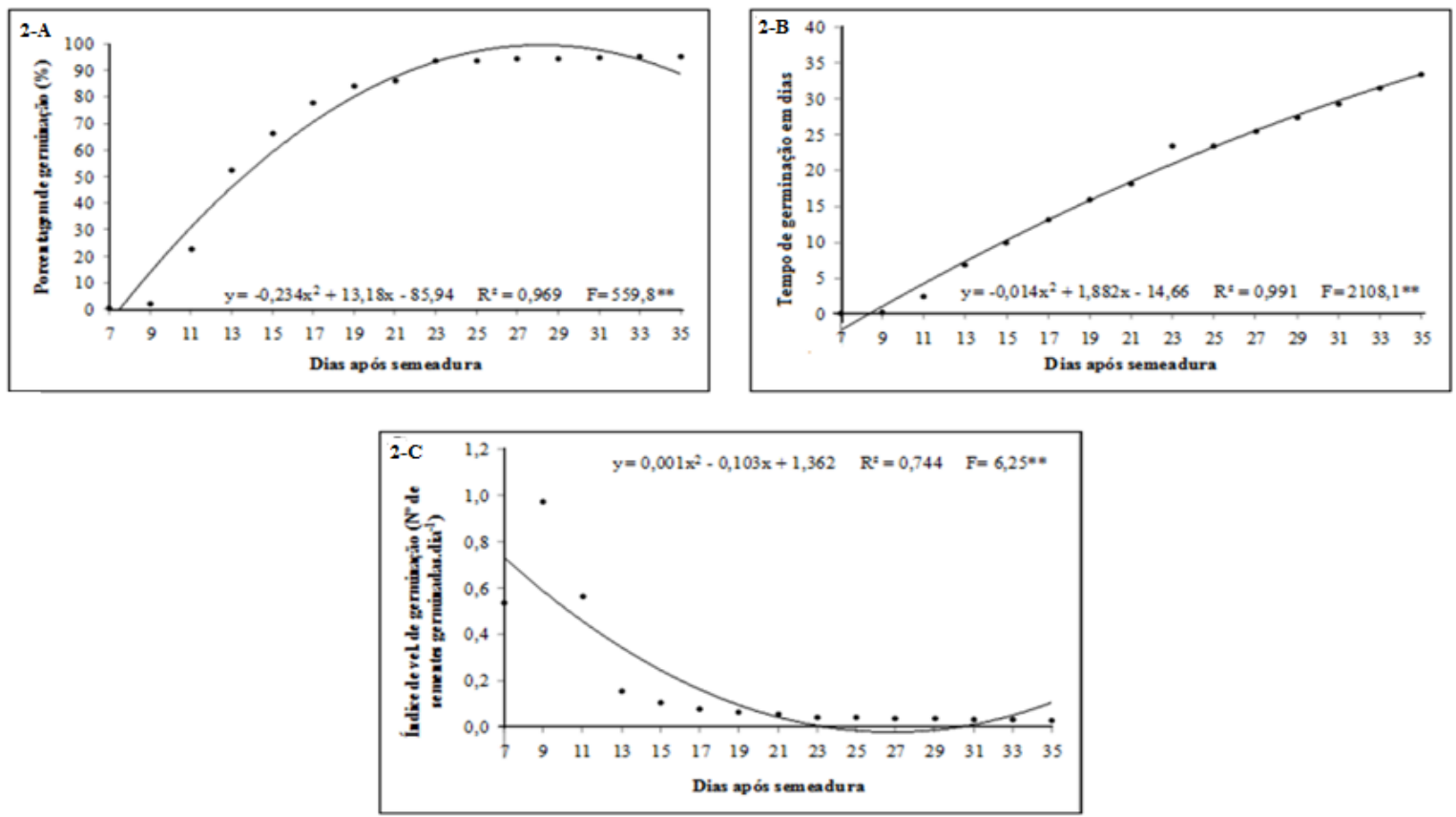

Figura 2. Porcentagem de germinação (A), tempo médio de germinação e índice de velocidade de germinação (C) em função dos dias após a semeadura. Botucatu, 2012.

Houve decréscimo quadrático no índice de velocidade de germinação das sementes, ajustando-se modelo de regressão quadrático em função dos dias após a semeadura (Figura 2). Prado Neto et al. (2007) relataram que em sementes de jenipapo pode possuir ácido giberélico que certamente concorreu para a promoção da velocidade de germinação e consequentemente maiores índices de velocidade de germinação, como também para o alongamento celular o que proporcionou plântulas com raízes e comprimento total maiores, em relação ao controle. Salienta-se que, as doses utilizadas neste experimento foram insuficientes para proporcionar aumento na germinação de sementes de abiu, sendo assim, 
são necessários novos estudos com uso de reguladores vegetais em sementes e mudas de abieiros.

\section{CONCLUSÃO}

Os abieiros cultivados em clima subtropical apresentam baixa variação química, possuindo elevado teor de sólidos solúveis, o que pode ser um incremento pela aceitação do fruto no mercado no consumo in natura.

O uso de ácido giberélico, nas doses utilizadas, não apresenta efeito sobre a germinação das sementes de abieiro e a maior porcentagem de germinação acontece após 28,2 dias da semeadura.

O abieiro cultivado em região subtropical apresenta grande potencial de exploração para produção de frutos de boa qualidade e seus derivados.

\section{REFERÊNCIAS BIBLIOGRÁFICAS}

ARAGÃO, C. A.; DEON, M. D.; QUEIROZ, M. A., DANTAS, B. F. Germinação e vigor de sementes de melancia com diferentes diploidias submetidas a tratamentos prégerminativos. Revista Brasileira de sementes, Pelotas, v. 28, n. 3, p.82-86, 2006.

ARAÚJO, P. C.; NETO, A. C. A.; SANTOS, S. R. N.; MEDEIROS, J. G. F.; LEITE, R. P.; ALVES, E. U.; BRUNO, R. L. A.; OLIVEIRA, J. J. F. Biometria de frutos e sementes de Operculinama crocarpa (L.) Urban ocorrente no semiárido norte-rio-grandense. Scientia Plena, Aracaju, v. 8, n. 4, p.1-5, 2012.

BEZERRA, F. T. C.; ANDRADE, L. A.; BEZERRA, M. A. F.; PEREIRA, W. E.; FABRICANTE, J. R.; OLIVEIRA, L. S. B.; FEITOSA, R. C. Biometria de frutos e sementes e tratamentos pré-germinativos em Cassia grandis L. f. (Fabaceae). Semina: Ciências Agrárias, Londrina, v. 33, supl. 1, p.2863-2876, 2012.

CANUTO, G. A. B.; XAVIER, A. A. O.; NEVES, L. C.; BENASSI, M. T. Caracterização físico-química de polpas de frutos da Amazônia esua correlação com a atividade anti-radical livre. Revista Brasileira de Fruticultura, Jaboticabal, v. 32, n. 4, p.1196-1205, 2010.

CARVALHO, N. M.; NASCIMENTO, W. M. O.; MULLER, C. H. Características físicas e de germinação de sementes de espécies frutíferas nativas da Amazônia. Boletim de Pesquisa. n. 203. Belém: Embrapa, 1998. 18 p. Disponível em: http://www.infoteca.cnptia.embrapa.br/infoteca/handle/doc/376633 . Acesso em: 10 nov. 2013.

CARVAlHO, J. E. U.; MÜLlER, C. H. Biometria e Rendimento Percentual de Polpa de Frutas Nativas da Amazônia. Comunicado Técnico. n. 139. Belém: Embrapa, 2005. 3 p. Disponível em: http://www.infoteca.cnptia.embrapa.br/infoteca/handle/doc/404792 . Acesso em: 10 nov. 2013.

Cultura Agronômica, Ilha Solteira, v.26, n.4, p.530-539, 2017 
CRUZ, E. D.; CARVALHO, J. E. U. Biometria de frutos e sementes e germinação de curupixá (Micropholis cf. venulosa Mart. e Eichler - Sapotaceae). Acta Amazonica, Manaus, v. 33, n. 3, p.389-398, 2003.

DONADIO, L. C.; MARTINS, A. B. G.; VALENTE, J. P. Fruticultura Tropical. Jaboticabal: Funep, 1992. 268 p.

GUSMÃO, E.; VIEIRA, F. A.; FONSECA JÚNIOR, E. M. Biometria de frutos e endocarpos de murici (Byrsonima verbascifolia Rich. Ex. A. Juss). Revista Cerne, Lavras, v. 2, n. 1, p.84-91, 2006.

KHAN, A. A. Incorporation of bioactive chemicals into seeds to alleviate environmental stress. Acta Horticulturae, Wageningen, v. 83, n. 2, p.2255-2264, 1978.

LEONEL, S.; ONO, E. O.; RODRIGUES, J. D. Germinação de sementes de tangerina Sunki. Laranja, Cordeirópolis, v. 14, n.2, p.551-564, 1993.

NASCIMENTO, W. M. O.; CARVALHO, J. U.; MULlER, C. H. Propagação do abieiro. Documentos. n. 249. Belém: Embrapa Amazônia Oriental, 2006. 20 p.,Disponível em: https://www.embrapa.br/busca-de-publicacoes/-/publicacao/410248/propagacao-do-abieiro.

Acesso em: 10 nov. 2013.

NATALE, W.; PRADO, R. M.; LEAL, R, M.; FRANCO, C. F. Efeitos da aplicação de zinco no desenvolvimento, no estado nutricional e na produção de matéria seca de mudas de maracujazeiro. Revista Brasileira de fruticultura, Jaboticabal, v. 26, n. 2, p.310-314, 2004.

PINTO. P. A. Pós colheita de abiu, bacupari e camu-camu, nativos da Região Amazônica, cultivados no estado de São Paulo. 2013. 145 f. Tese (Doutorado em Ciências/Fitotecnia) - Escola Superior de Agricultura "Luiz de Queiroz", Universidade de São Paulo, Piracicaba, 2013.

PRADO NETO, M.; DANTAS, A. C. V. L.; VIEIRA, E. L.; ALMEIDA, V. O. Germinação de sementes de jenipapeiro submetidas à pré-embebição em regulador e estimulante vegetal. Ciência e Agrotecmologia, Lavras, v. 31, n.3, p.693-698, 2007.

RAMOS, M. B. P.; FERRAZ, I. D. K. Estudos morfológicos de frutos, sementes e plântulas de Enterolobium schomburgkii Benth. (Leguminosae-Mimosoideae). Revista Brasileira de Botânica, São Paulo, v. 31, n. 2, p.227-235, 2008.

RUFINO, M. S. M.; ALVES, R. E.; FERNANDES, F. A. N.; BRITO, E. S. Free radical scavengin behavior of tem exotic tropical fruits extracts. Food Research International, Toronto, v. 44, n. 2011, p.2072-2075, 2010.

SEGANTINI, D. M.; LEONEL, S.; LIMA, G. P. P.; COSTA, S. M.; RAMOS, A. R. P. Caracterização da polpa de pêssegos produzidos em são Manuel-SP. Ciência Rural, Santa Maria, v. 42, n. 1, p.52-57, 2012.

Cultura Agronômica, Ilha Solteira, v.26, n.4, p.530-539, 2017 
TAIZ, L.; ZEIGER, E. Plant Physiology. 5. ed. Sunderland: Sinauer Associates, 2010. $700 \mathrm{p}$.

VIRGOLIN, L. B. Caracterização Físico-Química de Polpas de Frutas do Bioma Amazônia. 2015. 58 f. Dissertação (Mestrado em Engenharia e Ciência de Alimentos) Instituto de Biociências, Letras e Ciências Exatas, Universidade Estadual Paulista "Júlio de Mesquita Filho”, São José do Rio Preto, 2015. 